\title{
Inducible Ribosomal RNA Methylation in Streptomyces lividans, Conferring Resistance to Lincomycin
}

\author{
By GAIL JENKINS, MAGDALENA ZALACAIN AND ERIC CUNDLIFFE* \\ Department of Biochemistry and Leicester Biocentre, University of Leicester, \\ Leicester LEI 7RH, UK
}

(Received 17 April 1989; revised 13 July 1989; accepted 4 September 1989)

Streptomyces lividans TK21 possesses inducible ribosomal RNA methylase activity that confers high-level resistance to lincomycin and lower levels of resistance to certain macrolides. The methylase gene (designated $/ \mathrm{rm}$ ) is inducible by erythromycin and other macrolides and also by celesticetin (a lincosamide) but not by lincomycin. The $\mathrm{lrm}$ enzyme monomethylates the $\mathrm{N}^{6}$ amino group of adenosine at position 2058 within 23S-like ribosomal RNA.

\section{INTRODUCTION}

Antibiotic-producing organisms are a rich source of resistance determinants, some of which encode products that resemble in their action the enzymes responsible for resistance in clinical isolates. In particular, a growing number of actinomycetes that produce inhibitors of protein synthesis have been shown to possess methylases that render ribosomes resistant to such drugs, thereby affording the means to avoid self-intoxication. Such methylases (invariably, to date) act on ribosomal RNA (rRNA) at single specific sites, characteristic of given resistance phenotypes, and utilize $S$-adenosylmethionine (SAM) as cofactor (for a review, see Cundliffe, 1989).

Among the resistance phenotypes that can be attributed to specific methylation of RNA, the so called 'MLS' character has received considerable attention. For example, the erythromycin producer Saccharopolyspora erythraea (formerly Streptomyces erythraeus; Labeda, 1987), contains a resistance gene designated ermE, whose product dimethylates residue A-2058 within $23 \mathrm{~S}$ rRNA (Skinner et al., 1983). Both methyl groups are introduced into the $N^{6}$-amino group of the purine ring of A-2058 and, as a result, the ribosome becomes highly resistant to a diverse group of antibiotics, namely the macrolides, lincosamides and streptogramin type B families - hence MLS. [Here, the 23S-like rRNA from actinomycetes is referred to as ' $23 \mathrm{~S}$ ' although its sedimentation behaviour has not been studied. Also, for ease of reference, the numbering system for Escherichia coli $23 \mathrm{~S}$ rRNA is used. This is a valid device given the extent to which rRNA structure has been conserved during evolution. For a review, see Noller (1984).]

Since erythromycin itself is a macrolide, the presence in Sac. erythraea of a gene such as ermE can readily be rationalized. It is a powerful resistance determinant and, being constitutively expressed, renders the erythromycin producer essentially insensitive to the autogenous antibiotic. However, erm-type genes are by no means confined to the producers of MLS antibiotics. The MLS resistance phenotype was first encountered in clinical strains of Staphylococcus aureus and the general features of the resistance mechanism were elucidated using the product of the ermC gene from Staphylococcus (Lai et al., 1973). Later, inducible control of erm $C$ expression was shown to occur post-transcriptionally via a mechanism known as 'translational attenuation'. This involves conformational transitions in the leader sequence of erm C mRNA that activate previously inactive mRNA for translation (for reviews, see Dubnau,

Abbreviations: MLS, macrolide-lincosamide-streptogramin type B; SAM, S-adenosylmethionine. 
1984; Weisblum, 1984). Not least because of the novelty of translational attenuation in the context of prokaryotic gene control, MLS resistance and the determinants thereof have attracted considerable attention and have now been detected in a broad range of organisms, of both Gram types, including species of Streptomyces that do not obviously produce MLS compounds.

The starting point for the present work was the observation, made several years ago in this laboratory (R. H. Skinner, unpublished data), that Streptomyces lividans possesses an inducible resistance character involving macrolide antibiotics and lincomycin. Since $S$. lividans is currently the favourite surrogate host for genes isolated from other actinomycetes, and since there is a continuing interest in this laboratory in resistance determinants isolated from the producers of macrolides and lincosamides, we decided to investigate in detail the intrinsic resistance of $S$. lividans to such compounds.

\section{METHODS}

Bacterial strains and media. Streptomyces lividans strain TK21 (Hopwood et al., 1983) was obtained from Professor D. A. Hopwood, John Innes Institute, Norwich, UK. S. lividans AT391 was constructed from strain TK 21 by Dr A. S. Thiara in this laboratory and contains the plasmid pLST391, a pIJ702 derivative containing the ermE gene from Sac. erythraea as a $\mathrm{KpnI}$ fragment. Both strains were maintained at $30^{\circ} \mathrm{C}$ on NE agar plates (Skeggs et al., 1985). For liquid cultures, also grown at $30^{\circ} \mathrm{C}$, YEME medium supplemented with $5 \mathrm{mM}-\mathrm{MgCl}_{2}$ and $0.5 \%(\mathrm{w} / \mathrm{v})$ polyethylene glycol 6000 was used. YEME medium contained (per litre) $3 \mathrm{~g}$ yeast extract, $3 \mathrm{~g}$ malt extract, $5 \mathrm{~g}$ peptone and $10 \mathrm{~g}$ glucose. In order to induce resistance in $S$. lividans, erythromycin $\left(20 \mu \mathrm{g} \mathrm{ml}^{-1}\right.$, final concentration) was added to solid or liquid media.

MIC determinations. Minimum inhibitory concentrations were determined on NE agar plates containing drugs. Growth was monitored after $3-4 \mathrm{~d}$ at $30^{\circ} \mathrm{C}$.

Antibiotics. These were obtained as follows: lincomycin and celesticetin (Upjohn), tylosin (Eli Lilly), carbomycin (Pfizer), spiramycin (May \& Baker), and erythromycin (Sigma).

Preparation of mycelial extracts and salt-washed ribosomes. These were prepared as described previously (Skeggs et al., 1985). When $30000 \mathrm{~g}$ supernatant (S30) was to be used as the source of methylase activity, it was supplemented with glycerol $\left(10 \%, \mathrm{v} / \mathrm{v}\right.$, final concentration) in order to preserve activity during storage at $-70^{\circ} \mathrm{C}$.

Coupled transcription-translation in vitro. The preparation and use of crude initiation factors and post-ribosomal supernatant, together with salt-washed ribosomes, in coupled transcription-translation of plasmid DNA has been described in detail elsewhere (Calcutt \& Cundliffe, 1989). Reaction mixtures contained optimized inputs of S100 and initiation factors together with $20-25 \mathrm{pmol}$ of salt-washed ribosomes and $1 \mu \mathrm{g}$ of pUC18. Protein synthesis was measured in the presence of $\left[{ }^{35} \mathrm{~S}\right]$ methionine as previously described (Thompson et al., 1984).

Preparation of crude ribosomal RNA methylase activity. This was obtained as a ribosomal salt-wash fraction, by centrifuging crude ribosomes through 'high-salt' buffer containing $20 \%(\mathrm{w} / \mathrm{v})$ sucrose as described elsewhere (Zalacain \& Cundliffe, 1989).

rRNA methylation. Total RNA (RNA 70) was extracted from $70 \mathrm{~S}$ ribosomes using $\mathrm{LiCl}$ plus urea as described previously (Fahnestock et al., 1974). Routinely, methylation assays $\left(100 \mu l\right.$ total volume) were carried out at $30^{\circ} \mathrm{C}$ and contained as substrate RNA $70(20 \mathrm{pmol})$ from uninduced mycelium together with $50 \mu \mathrm{l}$ of crude methylase (i.e. ribosomal wash fraction obtained from induced mycelium) plus $2.5 \mu \mathrm{Ci}$ of $S$-adenosyl[methyl $\left.{ }^{3} \mathrm{H}\right]$ methionine ( $\left[\right.$ methyl- $\left.{ }^{-3} \mathrm{H}\right] \mathrm{SAM} ; 500 \mathrm{mCi} \mathrm{mmol}^{-1}, 18.5 \mathrm{GBq} \mathrm{mmol}^{-1}$ ) as methyl donor cofactor. The buffer was $50 \mathrm{mM}$ HEPES/KOH ( $\mathrm{pH} 7.5$ at $20^{\circ} \mathrm{C}$ ), $7.5 \mathrm{mM}-\mathrm{MgCl}_{2}, 37.5 \mathrm{mM}-\mathrm{NH}_{4} \mathrm{Cl}, 3 \mathrm{~mm}-2$-mercaptoethanol. Incorporation of $\left[{ }^{3} \mathrm{H}\right]$ methyl groups into RNA was measured as described previously (Skeggs et al., 1985). In negative controls, RNA 70 from induced mycelium was used.

For bulk methylation of RNA 70, to allow identification of the radiolabelled residue, the assay mixture was scaled up by a factor of 3 and $15 \mu \mathrm{Ci}$ of $\left[\right.$ methyl $\left.-{ }^{3} \mathrm{H}\right] \mathrm{SAM}$ of increased specific activity $\left(15 \mathrm{Ci} \mathrm{mmol}^{-1}, 555 \mathrm{GBq}\right.$ $\mathrm{mmol}^{-1}$ ) was used. Incubation was for $60 \mathrm{~min}$ at $30^{\circ} \mathrm{C}$, after which the labelled RNA was recovered by phenol extraction and ethanol precipitation, dissolved in a small volume of water and stored at $-70^{\circ} \mathrm{C}$.

Identification of a methylated residue in RNA. Bulk methylated RNA $70(60 \mathrm{pmol})$ was hydrolysed using $1 \mathrm{M}-\mathrm{HCl}$ for $60 \mathrm{~min}$ at $100^{\circ} \mathrm{C}$ and the products were separated by descending chromatography on Whatman 3MM paper in solvent containing either 2-propanol/HCl/water $(170: 41: 39$, by vol.) or butanol/water/ammonia $(95: 14: 5$, by vol.) for $27 \mathrm{~h}$ or $16 \mathrm{~h}$ respectively. After drying, markers were detected under UV light, and the chromatogram tracks cut into strips $1 \mathrm{~cm}$ wide. Radioactivity was estimated by liquid-scintillation spectrometry.

In other experiments, methylated RNA ( $13 \mathrm{pmol}$ ) was incubated with nuclease $\mathrm{Pl}(10 \mathrm{units})$ for $3 \mathrm{~h}$ at $37^{\circ} \mathrm{C}$ in $25 \mathrm{~mm}$-sodium acetate (pH 5.3) to generate nucleoside- $5^{\prime}$-monophosphates. These were then analysed by twodimensional thin layer chromatography (TLC) on $0.1 \mathrm{~mm}$ cellulose (Machery-Nagel MN300) plates as described by Nishimura (1979). After spraying the plates with EnHance (New England Nuclear), the radiolabelled products were located by fluorography at $-70^{\circ} \mathrm{C}$. 
Location of a methylated residue within RNA. This was done using 120 pmol of RNA 70 that had been methylated in the presence of $30 \mu \mathrm{Ci}$ of $\left[\right.$ methyl $\left.{ }^{3} \mathrm{H}\right] \mathrm{SAM}$ at high specific activity $\left(15 \mathrm{Ci} \mathrm{mmol}^{-1} ; 555 \mathrm{GBq} \mathrm{mmol}{ }^{-1}\right)$. After incubation $\left(600 \mu \mathrm{l}\right.$ total volume) for $60 \mathrm{~min}$ at $30^{\circ} \mathrm{C}$, the reaction mixture was divided into two. To one half, crude ermE methylase (i.e. $7 \cdot 5 \mu \mathrm{l}$ of S30 from S. lividans AT391) was added together with a 150 -fold excess of unlabelled cofactor ( $0.5 \mathrm{~mm}$ final concentration) and incubation continued for a further $60 \mathrm{~min}$. As a negative control, further $S$. lividans methylase (i.e. $50 \mu \mathrm{l}$ of ribosomal wash fraction from induced strain TK21) was added to the other half of the reaction mixture under similar conditions. Labelled RNA was then phenol extracted and ethanol precipitated. Following acid hydrolysis, the products were analysed by descending chromatography on Whatman 3MM paper in solvent containing butanol/water/ammonia ( $95: 14: 5$, by vol.). The chromatogram was then dried and treated as above.

\section{RESULTS}

\section{Resistance phenotype of $S$. lividans}

When grown on NE plates containing subinhibitory concentrations of erythromycin, $S$. lividans TK21 becomes significantly more resistant to subsequent challenge with macrolides or, especially, lincomycin (Table 1). Moreover, erythromycin is not the only macrolide antibiotic that can induce the resistance phenotype. Using the rapid disc assay system (Fujisawa \& Weisblum, 1981), various other drugs were shown to induce resistance to lincomycin $(200 \mu \mathrm{g}$ $\mathrm{ml}^{-1}$, final concentration) on NE plates, although not as efficiently as erythromycin on a weight for weight basis (data not given). In decreasing order of induction efficiency these were celesticetin, oleandomycin, tylosin, spiramycin, and carbomycin, the latter being a very poor inducer. On the other hand, lincomycin (the drug against which resistance is most predominantly expressed) did not itself induce the resistance phenotype, nor did its semisynthetic derivative clindamycin.

\section{Mechanism of inducible resistance}

Lincomycin and the macrolides bind to bacterial ribosomes in mutually exclusive fashion and with $1: 1$ stoichiometry, thereby inhibiting protein synthesis (for a review, see Gale et al., 1981). Accordingly, it seemed reasonable to suspect that collateral resistance to these compounds might operate at the ribosomal level in induced cultures of $S$. lividans. This proved to be so when ribosomes were prepared from strain TK21 (grown in the presence and absence of erythromycin) and assayed for their response to lincomycin in a coupled transcriptiontranslation system in which all other components were derived from uninduced mycelium. Clearly (Fig. 1), ribosomes from the induced strain were highly resistant in vitro to lincomycin and were also significantly more resistant to macrolides than were the control particles. These data do not prove that the inducible resistance phenotype of $S$. lividans is due entirely to events affecting the ribosome; indeed, as discussed later, we believe that another resistance gene is also present in strain TK21. They did however reveal the existence in that strain of a novel ribosomal modification system, since the classical MLS resistance mechanism renders ribosomes more highly resistant to all of the macrolides than was observed here. Accordingly, it was decided to investigate the mechanism of inducible ribosomal resistance to lincomycin using erythromycin as the inducer.

\section{Table 1. MIC values of various antibiotics for $S$. lividans TK21}

$S$. lividans TK21 was grown on NE agar at $30^{\circ} \mathrm{C}$ with ('induced') or without ('uninduced') erythromycin $\left(20 \mu \mathrm{g} \mathrm{ml}^{-1}\right)$.

$\begin{array}{lcc}\text { Antibiotic } & \overbrace{\begin{array}{l}S \text {. lividans } \\ \text { uninduced }\end{array}}^{\mathrm{MIC}\left(\mu \mathrm{g} \mathrm{ml}^{-1}\right)} & \begin{array}{c}\text { S. lividans } \\ \text { induced }\end{array} \\ \text { Lincomycin } & 30-50 & >5000 \\ \text { Erythromycin } & 30-50 & 250-300 \\ \text { Tylosin } & 25-50 & 300-400 \\ \text { Carbomycin } & 50-100 & >1000\end{array}$



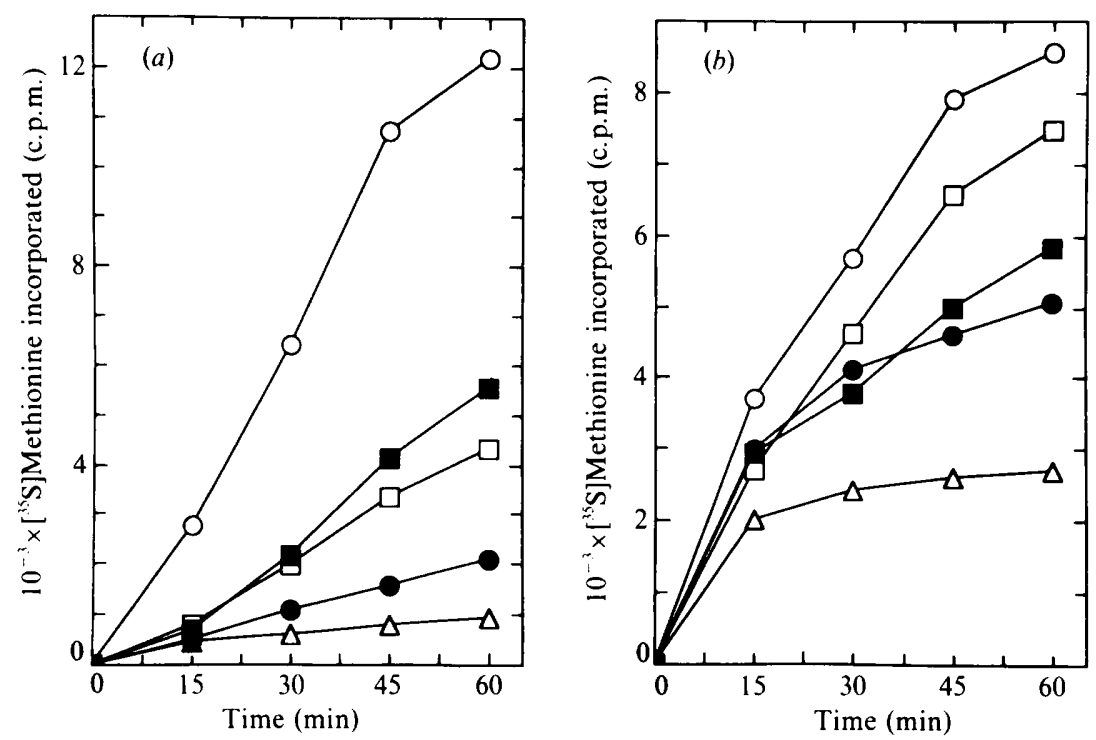

Fig. 1. Effects of antibiotics on protein synthesis by cell-free extracts of $S$. lividans. Drugs added were: $O$, no drug; , carbomycin $\left(0.5 \mu \mathrm{g} \mathrm{ml}^{-1}\right) ; \square$, lincomycin $\left(10 \mu \mathrm{g} \mathrm{ml}^{-1}\right) ; \mathbf{\square}$, erythromycin $\left(30 \mu \mathrm{g} \mathrm{ml}^{-1}\right)$; $\triangle$, tylosin $\left(1 \mu \mathrm{g} \mathrm{m}^{-1}\right)$. Ribosomes were from $S$. lividans TK 21 , uninduced $(a)$ or induced $(b)$ by growth in liquid medium containing erythromycin at $20 \mu \mathrm{g} \mathrm{ml}^{-1}$, final concentration.

\section{Methylation of $r R N A$}

Given our previous experience of resistance mechanisms involving methylation of rRNA and given also that the MLS resistance phenotype is conferred in that way, we decided to address directly the possibility that $S$. lividans TK 21 might possess inducible RNA methylase activity. In preliminary experiments (data not given), such activity was detected in crude S30 extracts of induced mycelium; subsequently, a ribosomal wash fraction was used as the source of methylase, together with [methyl $\left.{ }^{3} \mathrm{H}\right] \mathrm{SAM}$ as methyl donor and total rRNA (RNA 70) as substrate (Fig. 2). The latter was normally obtained from uninduced mycelium of strain TK21, although RNA 70 from induced mycelium was also prepared and used in negative controls. Methylation of RNA 70 from the uninduced strain occurred with a stoichiometry of about 0.5 and, in separate experiments (data not given), 23S RNA from the 50S ribosomal subunit was shown to be the substrate. This occurred only with free rRNA; 70S ribosomes or their $50 \mathrm{~S}$ subunits were not substrates for methylation.

In order to confirm that inducible methylation of 23S rRNA was indeed the cause of ribosomal resistance in $S$. lividans TK21, a mutant strain (constitutively resistant to high levels of lincomycin) was isolated following UV mutagenesis. The mutant possessed ribosomes that were indistinguishable from those of the induced parental strain in their response to antibiotics, and contained $23 \mathrm{~S}$ rRNA that was not a substrate for the inducible methylase activity described above (Fig. 2). Evidently, in that mutant strain, the normally inducible rRNA methylase was constitutively expressed.

\section{Specificity of $r$ RNA methylation}

Hydrolysis of [ ${ }^{3} \mathrm{H}$-methyl]RNA with $\mathrm{HCl}$ (which liberates purine bases, pyrimidine-3'mononucleotides and ribose phosphate) followed by paper chromatography revealed a single methylated species that was obviously a purine base. With 2-propanol/ $\mathrm{HCl}$ as the solvent, this material ran ahead of the adenine marker and co-migrated with $N^{6}, N^{6}$-dimethyladenine and $N^{6}$. monomethyladenine standards, which were incompletely resolved in this system. However, 


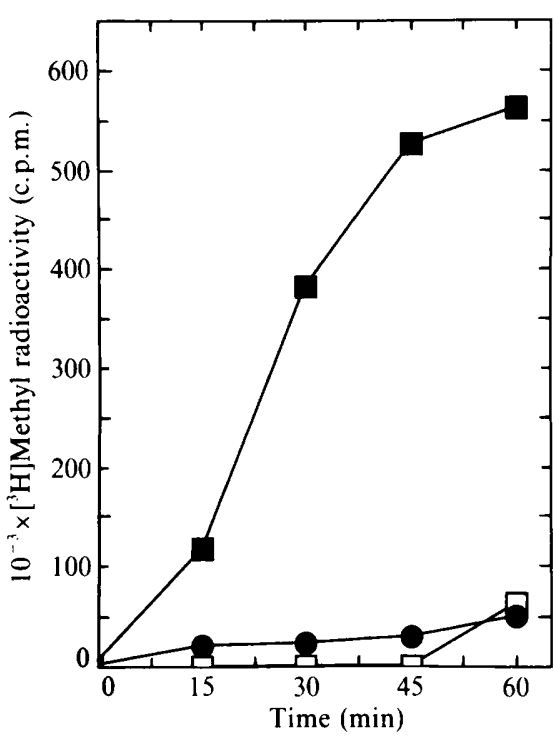

Fig. 2

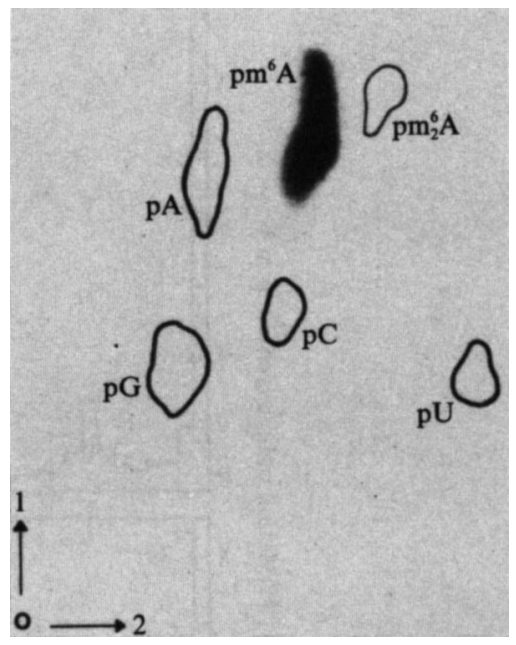

Fig. 3

Fig. 2. Methylation of rRNA in vitro. Extract from induced $S$. lividans was used as the source of methylase, together with $\left[\right.$ methyl $\left.-{ }^{3} \mathrm{H}\right]$ SAM as cofactor and RNA 70 from uninduced $S$. lividans TK 21 $(\square)$, induced $S$. lividans $(\square)$, and a mutant of $S$. lividans, constitutively resistant to lincomycin (O).

Fig. 3. Identification of a methylated nucleotide from rRNA. RNA 70 from uninduced $S$. lividans TK21 was modified in vitro using an extract from induced $S$. lividans as the source of methylase, plus [methyl$\left.{ }^{3} \mathrm{H}\right]$ SAM as cofactor. Methylated RNA was digested with nuclease P1 and products were separated by two-dimensional TLC. pA, pG, pU, pC, nucleoside-5'-monophosphates. A spot of radiolabelled material comigrated with $\mathrm{pm}^{6} \mathrm{~A}\left(N^{6}\right.$-methyladenosine-5'-phosphate). The position of pm ${ }_{2}^{6} \mathrm{~A}\left(N^{6}, N^{6}-\right.$ dimethyladenosine- $5^{\prime}$-phosphate) was determined in a parallel experiment and has been added. Origin $(\mathrm{O})$ and the direction of migration in both dimensions are indicated.

since the chromatographic mobility of purine bases in organic phases is most markedly enhanced by methylation of the amino group, and since the radiolabelled residue ran well ahead of $N^{2}$-dimethylguanine, it was clear that we were dealing with methylated adenine. When the radiolabelled (methylated) material was eluted from the paper using $20 \mathrm{mM}-\mathrm{HCl}$ and re-run in butanol/ammonia solvent, it co-migrated with authentic $N^{6}$-monomethyladenine and was clearly resolved from the dimethylated base (data not given, but see Fig. $4 a$ ). Confirmation that the modified residue was indeed $N^{6}$-monomethyladenine came from two-dimensional TLC (Nishimura, 1979) of nucleoside-5'-monophosphates following total digestion of in vitromethylated RNA with nuclease P1 (Fig. 3).

\section{Identification of the site of methylation within $23 S \mathrm{rRNA}$}

In order to locate the inducibly methylated base within the sequence of $S$. lividans $23 \mathrm{~S}$ rRNA (about 3120 nucleotides; J.L. Pernodet, personal communication), we took advantage of the known specificity of another methylase enzyme. Given the association between residue A-2058 of 23S rRNA and the MLS resistance phenotype, we compared the action of the ermE methylase (responsible for MLS resistance in Sac. erythraea) on rRNA from induced and uninduced $S$. lividans. The data (not given here) can be summarized briefly: RNA from the uninduced mycelium was methylated in vitro by the ermE methylase with about twice the stoichiometry of that from induced mycelium, suggesting the possibility that residue A-2058 might be inducibly monomethylated to confer lincomycin resistance in $S$. lividans. Accordingly, that hypothesis was tested directly. 


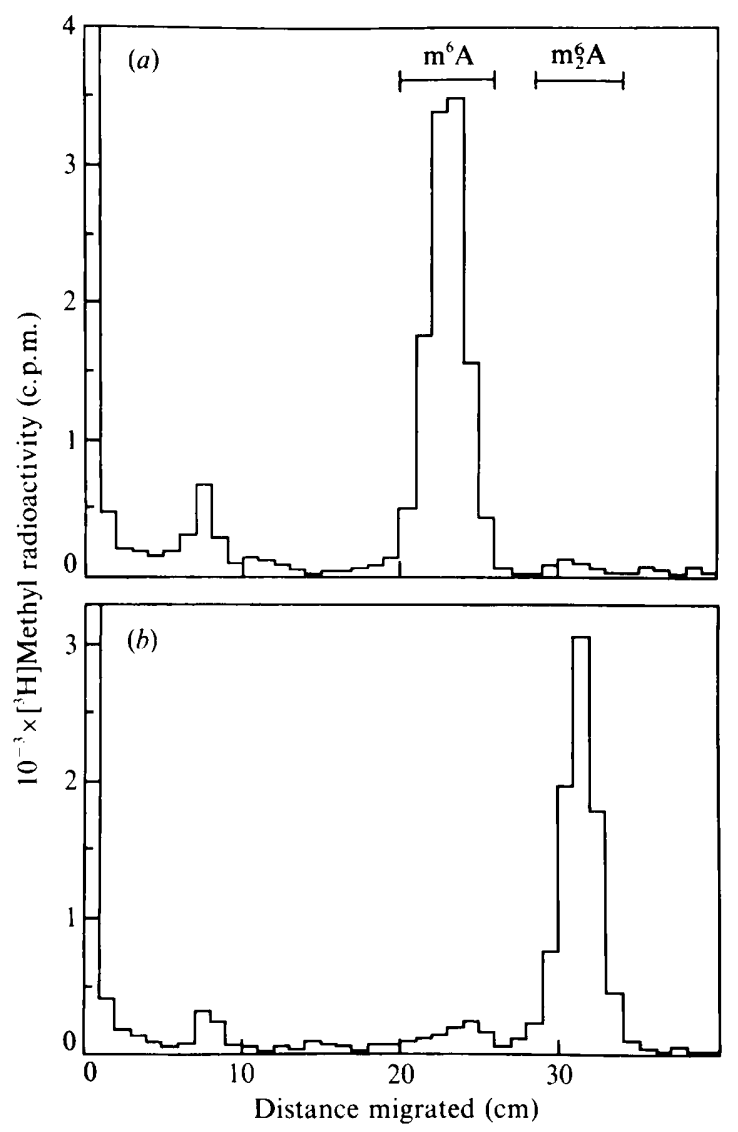

Fig. 4. Determination of the site of action of the inducible rRNA methylase in $S$. lividans. RNA 70 from uninduced $S$. lividans TK21 was methylated in vitro, using [methyl- $\left.{ }^{3} \mathrm{H}\right] \mathrm{SAM}$ plus an extract from induced $S$. lividans. Incubation was then continued for a further $60 \mathrm{~min}$ in the presence of excess unlabelled cofactor together with $(a)$ the inducible methylase native to $S$. lividans, or $(b)$ the ermE methylase. Methylated RNA was then phenol extracted, precipitated and hydrolysed using $1 \mathrm{M}-\mathrm{HCl}$, and the products subjected to paper chromatography in butanol/ammonia solvent. $\mathrm{m}^{6} \mathrm{~A}, N^{6}$. monomethyladenine; $\mathrm{m}_{2}^{6} \mathrm{~A}, N^{6}, N^{6}$-dimethyladenine.

In the decisive experiment, rRNA from uninduced $S$. lividans was modified in vitro using a ribosomal wash fraction from induced mycelium as the source of methylase activity and [methyl${ }^{3} \mathrm{H}$ ]SAM as cofactor. Following a $60 \mathrm{~min}$ incubation, during which radiolabelled methyl groups were incorporated into adenine within the 23S RNA, an excess of non-radioactive SAM was added (to prevent further radiomethylation) together with $\mathrm{S} 30$ (i.e. crude ermE methylase) from $S$. lividans AT391. Incubation was then continued at $30^{\circ} \mathrm{C}$ for a further $60 \mathrm{~min}$. As a control, some rRNA was radiolabelled as above and then incubation was continued with excess unlabelled cofactor in the presence of additional methylase from induced $S$. lividans. Both types of modified RNA were then hydrolysed with $\mathrm{HCl}$ and the products subjected to paper chromatography using butanol/ammonia solvent. When RNA had been exposed only to the inducible methylase from $S$. lividans, the radiolabelled product co-migrated with the $\mathrm{N}^{6}$ monomethyladenine standard (Fig. $4 a$ ) as expected from our other results given above. However, following the action of the ermE methylase on rRNA that had previously been radiomethylated by the inducible enzyme native to $S$. lividans, the bulk of the radiolabelled species now co-migrated with the $N^{6}$-dimethyladenine marker. Evidently, the adenine residue that had been monomethylated by the $S$. lividans enzyme had been further modified by the ermE product and must therefore have been located at position 2058 within the $23 \mathrm{~S}$ rRNA sequence. 


\section{DISCUSSION}

Prior to the present work, only one mechanism of ribosomal modification leading to lincomycin resistance had been described in detail, namely dimethylation of residue A-2058 within 23S rRNA, as in the classical MLS resistance mechanism of Staph. aureus or Sac. erythraea (Skinner et al., 1983). However, resistance to sub-sets of the MLS drugs had also been observed among Streptomyces, which clearly indicated the operation of additional mechanisms. During a survey of $23 \mathrm{~S}$ ribosomal RNA from various Streptomyces species, the presence of monomethyl- or dimethyladenine (or both) was noted in number of strains and provoked the speculation that rRNA methylation might account for resistance to macrolides and/or lincosamides and/or streptogramin B in those organisms (Graham \& Weisblum, 1979; Fujisawa $\&$ Weisblum, 1981). The present data confirm the plausibility of that idea and reveal that monomethylation of residue A-2058 within 23S rRNA leads primarily to lincomycin resistance, in contrast with dimethylation of the same residue, which not only leads to lincomycin resistance but also to high-level macrolide resistance (Zalacain \& Cundliffe, 1989). Accordingly, we propose the designation $l r m$ (lincomycin resistance methylase) for the inducible methylase gene native to $S$. lividans.

Quite why mono- and di-methylation of A-2058 should confer such markedly different resistance phenotypes is not clear, although the data obviously indicate subtle differences in the way that the various MLS antibiotics interact with the ribosome. Central to the issue is the question of whether MLS antibiotics interact directly with A-2058 within 23S ribosomal RNA. If not, the differential effects of mono- and dimethylation upon drug binding might be attributable to steric hindrance. Alternatively, the 6-amino group of A-2058 might be directly involved in drug binding. Interestingly, substitution of A-2058 by G within $23 \mathrm{~S}$ rRNA of Escherichia coli rendered ribosomes resistant to erythromycin, although their response to other MLS antibiotics was not reported (Vester \& Garrett, 1987).

In the future, we intend to study the mechanism whereby $\mathrm{lrm}$ is induced in S. lividans. Arguing by analogy with the ermC gene of Staph. aureus (despite the differences, detailed here, in the actions of their products) we suspect that translational attenuation might be involved and we note with interest the marked similarities in induction specificity between the two systems. In particular, the lincosamide antibiotic celesticetin induces both $\mathrm{lrm}$ and ermC whereas lincomycin induces neither. Since post-transcriptional induction of ermC according to the Weisblum-Dubnau model (see Introduction) involves 'stalling' of ribosomes during attempted translation of a specific leader (or control) sequence of the mRNA, this reveals, yet again, differences in the modes of action of the various drugs at the level of the ribosome. For lincomycin and celesticetin, some such differences have already been reported. For example, lincomycin inhibited the binding of model substrates (i.e. aminoacyl-oligonucleotides) to both the $\mathrm{A}$ and $\mathrm{P}$ sites of the ribosomal peptidyl transferase centre, whereas celesticetin inhibited neither (Celma et al., 1971).

In order to facilitate the proposed studies of $\mathrm{rm}$ induction the constitutive lincomycinresistant mutant (referred to earlier) was first selected. Then, a DNA fragment originating in the mutant was cloned in strain TK21 and shown to confer constitutively the resistance phenotype that is normally inducible in strain TK21 (G. Jenkins, unpublished data). However, a subfragment of that DNA, still containing lrm, confers a somewhat different phenotype (i.e. high-level resistance to lincomycin but with lesser resistance to macrolides). We therefore suspect that $S$. lividans harbours at least one more erythromycin-inducible resistance gene in addition to $\mathrm{lrm}$. This matter is currently under investigation.

This work was supported by a MRC research studentship awarded to Gail Jenkins. We also thank EMBO for a fellowship, awarded to Magdalena Zalacain.

\section{REFERENCES}

Calcutt, M. J. \& Cundliffe, E. (1989). Use of a fractionated, coupled transcription-translation system in the study of ribosomal resistance mechanisms in antibiotic-producing Streptomyces. Journal of General Microbiology 135, 1071-1081.
Celma, M. L., Monro, R. E. \& Vazquez, D. (1971). Substrate and antibiotic binding sites at the peptidyl transferase centre of $E$. coli ribosomes. Binding of UACCA-LEU to $50 \mathrm{~S}$ subunits. FEBS Letters 13, 247-251. 
Cundliffe, E. (1989). How antibiotic-producing organisms avoid suicide. Annual Review of Microbiology 43 (in the Press).

DubNaU, D. (1984). Translational attenuation: the regulation of bacterial resistance to the macrolidelincosamide-streptogramin B antibiotics. CRC Critical Reviews in Biochemistry 16, 103-132.

FaHNestock, S., ERdMANN, V. \& NomURA, M. (1974). Reconstitution of $50 \mathrm{~S}$ ribosomal subunits from Bacillus stearothermophilus. Methods in Enzymology 30, 554-562.

FujisawA, Y. \& Weisblum, B. (1981). A family of $\mathrm{r}$-determinants in Streptomyces spp. that specifies inducible resistance to macrolide, lincosamide and streptogramin type B antibiotics. Journal of Bacteriology 146, 621-631.

Gale, E. F., Cundliffe, E., Reynolds, P. E., RICHMOND, M. H. \& WARING, M. J. (1981). Molecular Basis of Antibiotic Action, 2nd edn. London: John Wiley.

Graham, M. Y. \& Weisblum, B. (1979). 23S ribosomal ribonucleic acid of macrolide producing streptomycetes contains methylated adenine. Journal of Bacteriology 137, 1464-1467.

HoPWOOD, D. A., Kieser, T., Wright, H. M. \& BibB, M. J. (1983). Plasmids, recombination and chromosome mapping in Streptomyces lividans 66. Journal of General Microbiology 129, 2257-2269.

LABEDA, D. P. (1987). Transfer of the type strain of Streptomyces erythraeus (Waksman 1923) Waksman \& Henrici 1948 to the genus Saccharopolyspora Lacey \& Goodfellow 1975, as Saccharopolyspora erythraea sp. nov., and designation of a neotype strain for Streptomyces erythraeus. International Journal of Systemic Bacteriology 37, 19-22.

LaI, C. J., Weisblum, B., FaHnestock, S. R. \& NomURA, M. (1973). Alteration of 23S ribosomal
RNA and erythromycin-induced resistance to lincomycin and spiramycin in Staphylococcus aureus. Journal of Molecular Biology 74, 67-72.

NishimuRA, S. (1979). Transfer RNA : Structure, Properties and Recognition, Appendix III, pp. 551-552. Edited by P. R. Schimmel, D. Söll \& J. A. Abelson Cold Spring Harbor, NY: Cold Spring Harbor Laboratory.

NOLLER, H. F. (1984). Structure of ribosomal RNA. Annual Review of Biochemistry 53, 119-162.

Skeggs, P. A., Thompson, J. \& Cundliffe, E. (1985). Methylation of $16 \mathrm{~S}$ ribosomal RNA and resistance to aminoglycoside antibiotics in clones of Streptomyces lividans carrying DNA from Streptomyces tenjimariensis. Molecular and General Genetics 200, $415-421$.

Skinner, R., Cundliffe, E. \& Schmidt, F. J. (1983). Site of action of a ribosomal RNA methylase responsible for resistance to erythromycin and other antibiotics. Journal of Biological Chemistry 258, 12702-12706.

Thompson, J., RaE, S. \& Cundliffe, E. (1984). Coupled transcription-translation in extracts of Streptomyces lividans. Molecular and General Genetics 195, 39-43.

VESTER, B. \& GarRetT, R. A. (1987). A plasmid-coded and site-directed mutation in $E$. coli $23 \mathrm{~S}$ RNA that confers resistance to erythromycin: implications for the mechanism of action of erythromycin. Biochimie 69, 891-900.

WeISBLUM, B. (1984). Inducible erythromycin resistance in bacteria. British Medical Bulletin 40, 47-53.

Zalacain, M. \& CUNDliffe, E. (1989). Methylation of $23 \mathrm{~S}$ ribosomal RNA due to $\operatorname{tr} \mathrm{A}(\mathrm{ermSF})$, a tylosin resistance determinant from Streptomyces fradiae. Journal of Bacteriology 171, 4254-4260. 